\title{
Analysis on Application of Hierarchical Teaching Method in Computer Teaching
}

\author{
Lei Guo ${ }^{1}$, Xin Wang ${ }^{1}$ \\ ${ }^{1}$ Mingde College, Northwestern Polytechnical University, Xi'an, 710124, China
}

\begin{abstract}
Keywords: computer science, hierarchical teaching; teaching requirements; teaching students according to their aptitude
\end{abstract}

\begin{abstract}
With the development of the society, people have more and more emphasized the quality-oriented education, computer science is also no exception, and the cultivation of professional computer talents has become the important objective and direction of teaching reform. However, the traditional teaching mode cannot meet the demand of teaching development at all, so the teaching mode is urgently to be reformed. Hierarchical teaching method can meet the demand for the professional teaching of computer major, because it is the hierarchical teaching according to the students' characteristics and conditions, really ensuring teaching students according to their aptitude and making students comprehensively developed and make overall progress.
\end{abstract}

\section{Introduction}

There exist many problems in our current teaching, with backward teaching mode and improper teaching methods, hindering the development of teaching. Therefore, it is the direction of education reform to further reform the teaching mode, improve the teaching quality and cultivate high-quality talents. In this paper, the backward teaching situation of the computer science is introduced first, second, the reason to adopt the hierarchical teaching is understood, and then the means to adopt hierarchical teaching in computer science are analyzed, and finally the advantages of using hierarchical teaching in computer science are summarized.

\section{Backward teaching situation of computer science}

The university computer teaching is restricted by difference factors in the traditional teaching, and it is difficult to ensure teaching according to the students' aptitude, brining many teaching problems. For example, there are different requirements for various majors, students have different learning interests, and the employment demands in the society are different. Furthermore, the backward computer teaching method is very difficult to meet students' different demands, and also difficult to make students comprehensively develop and jointly make progress, and even violates the principle of "people first" in teaching. Next, the backward teaching situation of computer science will be analyzed from the following aspects.

1. Backward teaching thought

Schools are the basic institution of education development and the cradle of talents cultivation, if this requirement is violated in teaching, all are empty talk. However, the objective fact is that there exist differences among the individual teaching targets. For example, the students have different foundations, learning interests and learning abilities, causing different scores; while the backward traditional teaching thought is common in every school, in order to pursuit the enrolment rate, the schools will stress on the education to the average students, with differentiated treatment in talents cultivation, which will inevitably cause two kinds of problems: first, the excellent students are easy to master the knowledge demand, so they do not have enough learning strength and have no spirit of thorough learning; second, the students with poor academic performance lose the confidence and interest of further study as they cannot catch up with the progress, so they despair with out any achievement. So there has always a contradiction between the backward teaching thought and the students' individual difference. The characteristics of hierarchical teaching are to teach according to 
the students' demands and abilities, making all students learn the practical knowledge and make progress, so as to meet the teaching requirements. Hierarchical teaching s a new teaching model, being the further performance of teaching mode, which can realize teaching according to the students' aptitude, so as to make students overall develop and comprehensively make progress.

2. Obsolete teaching contents

The traditional teaching mode has obsolete teaching contents, and is adverse to the improving of students' occupational ability. Over years, the teaching contents of the traditional courses have been updated rapidly, and teachers also follow the prescribed order in teaching, such course arrangement cannot stimulate the students' all potentials, and is beneficial for their improving of quality abilities and formation of innovative spirit, while hierarchical teaching, based on the principle of "expanded foundation and flexible module" in the course arrangement, really realized the layered and hierarchical teaching, which is beneficial to cultivate the students' occupation ability and also beneficial to make use of the students' potential, really achieving the purpose of talents cultivation and making students develop comprehensively.

3. Low employment rate

With the development of society, there is a greater demand on the computer talents, for example, enterprises do not only need computer operation talents, but also hardware repair talents and computer programming talents, and such employment demand proposes higher requirements for the talents cultivation. The traditional teaching is still aimed at the ordinary students, which has been unable to adapt to the requirements of teaching development. Therefore, in order to achieve the teaching requirements, especially for the purpose of meeting the employment demand, hierarchical teaching method must be used, only this way is to cultivate the students from the objective of occupational cultivation, making students take the initiative according to their professional skills, which cannot promote employment better, but can also make students accomplish tasks at east in their work post.

\section{Reason for hierarchical teaching in computer science}

\section{Different learning environments}

Different learning environments make students have differences in mastering of basic computer knowledge. For example, some students are from the rural areas, seldom contact computer, and it is until they enter university do they use the computer, with very little basic computer knowledge; while the students living in large cities might learn computer in primary school because of advantageous school conditions. Although there are fewer contents in the primary computer courses with low difficulty, these lay a good foundation for the students, having a great help for them to further learn computer in the future.

2. Different self-restrictions

Different self-restriction abilities of the college students cause different computer scores to students. Some teachers engaging in the computer teaching for many years summarize that some students who seldom contacted computer previously are curious about computers and are full interest in the computer operation, while the online chatting, network game and network video can attract the more, an these students with poor self-restriction will be indulged in the game, seriously influencing their learning to computer knowledge. Therefore, the self-restriction ability is an important factor to influence the students' scores, and these problems are caused by students themselves, but as long as the teachers guide and manage them, such phenomenon can also be controlled.

3. Different practical operations

Computer science is a discipline of practice, especially the hardware knowledge, which can be mastered only after more operations. However, according to the investigation to a university, only $12 \%$ of the students in the whole university can install the system and only $2 \%$ can install the hardware by themselves. Although there is no student majoring in computer in the statistics, this result is also unsatisfactory. From this we can see that the students master the practical contents of computer far from enough. Although the students are not majored in computer, and do not have a 
requirement for the mastering of computer skills, after all, practical operation is an effective means to improve the students' computer ability, and it is quite necessary to master certain operation knowledge.

\section{Different interests and hobbies}

Interests and hobbies are also important factors to influence the students' computer ability. Teaches with many years' teaching experience find that the active and open-minded students are more positive in class, who love operation, dare to consult questions and their computer operation ability is strong, while the stiff and introvert students are not so positive class and basically do not consult questions, and even if they have questions, they only ask the classmates, and will keep silent without even if they do not get the satisfactory answers, and these students are very poor in the computer operation ability.

Actually, almost all students love computer operation, just some students are keener on some aspect. For example, according to the questionnaire on students of class, $70 \%$ like playing games, $15 \%$ like painting, $10 \%$ like typewriting and $5 \%$ have other interests. So it can be seen that the students' loving to computer is dominated by playing game. It is just because they have such learning motives that they have so large differences in academic performance, and this requires the teachers to do more work, and how to guide the students to become interest in the teaching contents is the key to improve the teaching performances.

\section{Means to adopt hierarchical teaching in computer science}

\section{Hierarchy to the teaching targets}

Hierarchy to the teaching targets can ensure the teaching according to the students' aptitude and makes students comprehensively develop and make progress overall. In the implementation, first questionnaire is conducted to the students to know about the basic condition of the students' mastering to knowledge, and then group teaching is conducted according to the students' condition, generally there is foundation learning group, ordinary knowledge learning group and profound knowledge learning group, and group change learning is also available according to the students' knowledge mastering information, in this way the demands of the students with more progress can be met, so as to ensure dynamic teaching and teaching according to the students' aptitude really.

2. Hierarchy to teaching objective

The students master the basic knowledge in different extents, so hierarchy to the teaching objective conforms to the actual teaching condition more. The teachers layer the learning objective according to the students' hierarchy, which ensures that the students have learning objective conforming to their actual condition, so that they have a high learning strength and their academic performances will be improved.

In the actual teaching, teachers can layer the objective according to three groups of the students, respectively basic objective, general objective and improved objective. Although the three objectives are established according to the students' grouping, they arte not the compulsory requirements that must be completed by the students, but only urge the students to learn, as for whether the objective can be reached or surpassed, it is the students' automatic behavior and cannot be punished or awarded materially.

3. Hierarchy to teaching mode

Since hierarchical teaching is conducted to the students, it is needed to set different teaching modes to meet the students' different demands. Therefore, it is required to set the teaching mode according to the students' knowledge mastering degree and learning recognition abilities. That is to say, select the teaching contents conforming to the students for teaching, and then teach according to the students' characteristics in teaching method, only in this way can the characteristics of hierarchical teaching be met, so as to achieve the overall development and overall progress of the students. For example, the students in the group of basic knowledge learning generally are weak in the basic knowledge with not high learning ability. There will be some difficulties in the teachers' oral interpretation, and generally a good teaching effect cannot be reached. In this case, if the students 
use multimedia technology for teaching and play more teaching videos to the students, there might be a good effect; while the students in the group of profound knowledge learning generally have solid basic knowledge and a strong learning ability, so the teachers may adopt inquiry teaching method, design learning tasks for the students and make students learn independently to complete the task, so as to be beneficial for the cultivation of the students' self-learning ability and innovative spirit. Therefore, the hierarchy to the teaching mode can meet different learning demands of the students and improve the students' overall ability, so that students of various hierarchies can make progress.

4. Hierarchy to the operation contents

Different hierarchies of students require to adjust the teaching contents in the actual computer teaching. Take the inquiry teaching as an example, in the computer operation class, due to different student hierarchies, it is required to set different operation contents for practice by the students, only this way is the hierarchical teaching, and in this way, all students can complete the practice tasks conforming to their actual condition, so as to obtain harvest and improve their operation ability really. On the contrary, if the difference between the operation contents and the students' operation ability is too large, the practice will be meaningless.

5. Hierarchy to the evaluation method

Evaluating the students' learning effect scientifically and accurately is beneficial for the development and improvement of the teaching. Therefore, adopting hierarchical evaluation can evaluate the students' condition more accurately. In the actual teaching, the students would have theoretical knowledge examination and computer operation in each learning stage, and teachers may make a reasonable evaluation according to these contents, learn the learning effect through comparison and determine the students' real ability.

\section{Advantages of adopting hierarchical teaching in computer science}

\section{More reasonable cultivation}

Hierarchical teaching can ensuring the teaching according to the students' aptitude and is also more reasonable for the cultivation of talents. In teaching, the teachers layer according to the students' mastering to the basic knowledge and adjust the teaching contents and methods for different layers of students and arrange the teaching in a targeted way, in which way, all levels of students can make progress, so as to achieve a good teaching effect.

2. More flexible tutoring

Hierarchical teaching is beneficial for the students' tutoring, making that all students can get help from teachers. Aimed the characteristics of hierarchical teaching, teachers can adopt the hierarchical tutoring for cooperation. For example, teacher may adopt the tutoring method of individual tutoring, collective tutoring, group tutoring and classified tutoring and the diversified tutoring methods can achieve a better tutoring effect and improve the students' overall performance.

3. Instruction in place more

Hierarchical teaching is beneficial for the students to carry out the instruction and makes students complete the teaching tasks better. For example, in computer practice class, teachers may guide the students with strong ability to complete the difficult operation tasks; guide the students with ordinary learning ability to complete the ordinary operation tasks and guide those who with a poor learning ability to complete the operation tasks by step. Instruction in this way conforms to the students' learning requirements and is also beneficial for teachers' better tutoring.

4. More effective practice

Hierarchical teaching method can improve the students' incentives of operation and practice, so as to achieve a good teaching effect. All students have learning objective conforming to their actual condition, so the students have their own tasks in the process of practice, so as to improve the practice efficiency, making the practice effect more satisfactory. Furthermore, the students also experience the joy after completion the tasks in practice, so that their learning interest is stronger.

5. Clearer objective 
The teaching objective of the hierarchical teaching is clearer and is beneficial for the improving of teaching efficiency. In teaching, as the teachers carry out hierarchical teaching to the students and establish teaching objective conforming to the actual condition for the students, the students are easier to complete the tasks, in this way, their learning efficiency is improved, so is the teaching quality.

\section{Conclusion}

Hierarchical teaching method has significant advantages in the teaching of computer science, but schools have a short period to carry out the hierarchical teaching, so many problems will occur inevitably. Therefore, teachers majored in computer must assume the liability, strengthen research on the hierarchical teaching, further improve the implementation plan of hierarchical method, so as to make the hierarchical teaching method play a better teaching effect, improve the students' academic performances, and cultivate the students into excellent computer talents.

\section{References}

[1] Han Hongxia, Brief Discussion on the Application of Hierarchical Teaching Method in Computer Teaching of Secondary Vocational Education [J] Scientific \&Technological Innovation and Application, 2012(28)

[2] Xu Min, Brief Discussion on Application of Hierarchical Teaching Method in Computer Science [J] Examination Weekly, 2009(41)

[3] Lin Zhong, Experimental Research on Hierarchical Teaching Method in Computer Teaching of Vocational Schools [J] Journal of Jilin Provincial Institute of Education (discipline edition), 2009 (03)

[4] Zhang Qinhua, Discussion on Hierarchical Teaching Method in Computer Teaching [J] Journal of Hebei Engineering and Technical College 